\title{
ФУНДАМЕНТАЛИЗАЦИЯ ПЕДАГОГИЧЕСКОГО И ПРОФЕССИОНАЛЬНОГО ОБРАЗОВАНИЯ СПОСОБСТВУЕТ ЦЕЛОСТНОМУ ВОСПРИЯТИЮ НАУЧНОЙ КАРТИНЫ ОКРУЖАЮЩЕГО МИРА, ИНТЕЛЛЕКТУАЛЬНОМУ РАСЦВЕТУ ЛИЧНОСТИ
}

\section{THE FUNDAMENTALIZATION OF \\ PEDAGOGICAL AND PROFESSIONAL EDUCATION CONTRIBUTES TO THE HOLISTIC PERCEPTION OF THE SCIENTIFIC PICTURE OF THE WORLD AROUND US, THE INTELLECTUAL FLOURISHING OF THE INDIVIDUAL}

N. Botvineva

A. Moskvitin I. Ivanova

Summary: The main goal of our research is to form a competent specialist who is ready for continuous self-development and self-education. The methodological basis of the research was the concepts of integral and systematic approaches at the General scientific level; at the concrete scientific level-the concepts of axiological, cultural, personal activity, polysubject (Dialogic) approaches to the study of pedagogical phenomena.

As a basis for fundamentalization, the author proclaims the creation of such a system and structure of education, the priority of which is not pragmatic, highly specialized knowledge, but methodologically important, long-lived and invariant knowledge that contributes to the holistic perception of the scientific picture of the world around us, the intellectual flourishing of the individual and its adaptation to rapidly changing socio-economic and technological conditions.

Keywords: fundamentalization, formation of a competent specialist, modern scientific picture of the world, analytical rationality, pedagogical and professional education.

\author{
Ботвинева Наталья Юрьевна \\ дочент, Филиал ГБОУ ВО «Ставропольский \\ государственный педагогический институт» \\ в г. Ессентуки \\ botvineva@yandex.ru \\ Москвитин Анатолий Алексеевич \\ професссор, Филиал ГБОУ ВО «Ставропольский \\ государственный педагогический институт» \\ в г. Ессентуки \\ moskvit47@mail.ru \\ Иванова Ирина Борисовна \\ старший преподаватель, Филиал ГБОУ ВО \\ «Ставропольский государственный педагогический \\ институт» в г. Ессентуки \\ irinagern@yandex.ru
}

Аннотация: Основная цель нашего исследования заключается в формировании компетентного специалиста, готового к непрерывному саморазвитию и самообразованию.

Методологической основой исследования явились на общенаучном уровне - концепции целостного, системного подходов; на конкретно-научном уровне - концепции аксиологического, культурологического, личностнодеятельностного, полисубъектного (диалогического) подходов к изучению педагогических явлений.

В качестве основы фундаментализации провозглашается создание такой системы и структуры образования, приоритетом которых являются не прагматические, узкоспециализированные знания, а методологически важные, долго живущие и инвариантные знания, способствующие целостному восприятию научной картины окружающего мира, интеллектуальному расцвету личности и ее адаптации в быстроизменяющихся социально-экономических и технологических условиях.

Ключевые слова: фундаментализация, формировании компетентного специалиста, современная научная картина мира, аналитическая рациональность, педагогическое и профессиональное образования.

культурную ситуацию, но формирование представлений о закономерностях ее развития и тем самым о возможности ее изменения.

Основная цель нашего исследования заключается в формировании компетентного специалиста, готового к непрерывному саморазвитию и самообразованию.

Методологической основой исследования явились 
на общенаучном уровне - концепции целостного, системного подходов; на конкретно-научном уровне концепции аксиологического, культурологического, личностно-деятельностного, полисубъектного (диалогического) подходов к изучению педагогических явлений.

В ходе исследования был использован комплекс методов диагностические, экспериментальные, теоретические. Современное социокультурное общество предъявляет новые требования к системе образования. Новый образ образовательного пространства меняет отношение к личности, акцентирует повышенное внимание на его неповторимые индивидуальные свойства: направленность, особенности психики и способности. Вместе с этим меняется стиль преподавания, появляется необходимость в создании и применении в процессе обучения новых методик, новых форм обучения с использованием ИКТ.

Важными становятся уровень знаний обучающегося ,умение их применять в той или иной ситуации, умение самостоятельно добывать необходимую информацию, в соответствии с изменениями, овладевать новыми навыками и способностями, в рамках новой общественной ситуации менять свою программу развития и обучающегося.

В области образовательного процесса возникают принципиально новые тенденции развития научного знания, которые привели к воссозданию общенаучной картины мира как целостной системы научных представлений о природе, человеке и обществе. [2]

Возникает необходимость в определении принципиально новых идей в современной педагогической деятельности, что за собой влечет создание новых методик и технологий преподавания естественно-научного цикла предметов, которые основаны на прямой и обратной связи преподавателя и обучающегося. Эти идеи не вписываются в традиционное обучение. Вопрос о поисках новых возможностей в образовательном пространстве, новых ценностей современной технологии обучения сейчас стоит очень остро. В новом формате цивилизационного развития фундаментальных наук, таких как математика, физика, играют особую роль. Они не только обеспечивают технологический прогресс обучения и формируют новый менталитет общения преподавателя и ученика, глубинные структуры мышления, но и реализуют свои гуманитарные функции. Естественнонаучный цикл наук формируют особый тип рациональности, рациональности критически-аналитической [3]. Формируют новые принципы и методики преподавания фундаментальных наук естественно-научного цикла. Наступает новый этап очень важный для современного образовательного процесса, для современного уровня культуры способ мышления.
Анализируя и обобщая смысл происходящих изменений в образовательном пространстве при изучении естественно-научного цикла дисциплин, можно утверждать, что цивилизация и культура сегодня обязаны именно естественным наукам новым смыслом познания. На смену примитивному представлению о знаниях, приходит новое понимание всеобщей взаимосвязанности.

В качестве основы фундаментализации провозглашается создание такой системы и структуры образования, приоритетом которых являются не прагматические, узкоспециализированные знания, а методологически важные, долго живущие и инвариантные знания, способствующие созданию новых форм и методов обучения, интеллектуальному расцвету как преподавателя так и обучаемого и их адаптации в быстроизменяющихся социально-экономических и технологических условиях.

В разработанной А.Д. Сухановым концепции фундаментального учебного курса фундаментальность понимается не ex definicio, т.е. автоматически, соотнесенностью с фундаментальной областью научного знания, а соответствием ряду критериев, которые могут быть сформулированы следующим образом [5]:

- выполнение трех взаимосвязанных функций: образования, воспитания и развития;

- адекватность современным принципам структурирования научного знания в области изучения естественно-научного комплекса предметов;

- целостность курса на основе изучения всех его разделов вокруг стержневых методологических концепций, теорий и принципов;

- концентрированное и сбалансированное изложение наиболее фундаментальных законов и принципов науки с единых методологических позиций;

- формирование теоретического типа научного, рационального типа мышления личности и создание интеллектуального фундамента для ее саморазвития и саморазвития в изменяющихся внешних условиях. [4]

Таким образом, образование может считаться фундаментальным, если оно представляет собой процесс нелинейного взаимодействия, в первую очередь преподавателя с новой интеллектуальной средой, при котором личность воспринимает ее для обогащения собственного внутреннего мира и благодаря этому созревает для умножения потенциала самой среды

Задача фундаментального образования - обеспечить оптимальные условия для воспитания гибкого и многогранного научного мышления обучающихся, различных способов восприятия действительности, создать внутреннюю потребность в саморазвитии и самообразовании на протяжении всего периода обучения. Затем применения полученных знаний в дальнейшей жизни. 
В качестве основы фундаментализации провозглашается создание такой системы и структуры образования, приоритетом которых являются не прагматические, узкоспециализированные знания, а методологически важные, долго живущие инвариантные знания, способствующие целостному восприятию научной картины окружающего мира, интеллектуальному расцвету личности и ее адаптации в быстроизменяющихся социально-экономических и технологических условиях. [4]

Концепция фундаментализации может быть определена следующими требованиями.

1. Максимально отчетливое отображение сущности и особенностей мышления как развитой формы теоретического познания.

2. Максимальная целостность курса в рамках современной естественнонаучной картины мира с учетом единства предмета исследования, стрежневых математическо-физических подходов, фундаментальных математических и физических понятий, базовых моделей и важнейших проблем.

3. Направленность на последовательное инвариантное описание объектов и процессов природы на основе фундаментальных знаний, на последовательное изучение математических законов и определений.

4. Систематическое обучение методам программного моделирования предметов как специфической форме научного мышления и познания новых знаний и навыков.

5. Использование математического аппарата по принципу разумной достаточности.

Большинство традиционных научных дисциплин в последнее время существенно трансформировали. Потребность в индивидуализации образовательных программ обусловлена тем, что сфера профессиональных возможностей и профессиональной деятельности преподавателя значительно расширилась. [5]

Объектом его деятельности становится применение новых методик обучения в образовательном процессе, которые помогут формированию целостного знания обучающегося, и оно будет ключевым в научно-методических разработках дисциплин естественно-научного цикла.

Психолого-педагогические закономерности всестороннего развития личности позволяют, конструировать новые формы и методические в процессе обучения, которые будут эффективны в том случае, если будет проведен методический анализ сущности естественно-научной направленности наук, будут учтены закономерности индивидуального развития личности и гуманитарная направленность обучения естественно-научным дисциплинам будет выражена в новых формах и методах, усовершенствованных к новым образовательным стандартам, раскрывающих индивидуальные особенности мыслительной деятельности обучающихся.

Фундаментализация педагогического процесса состоит во взаимосвязанной совокупности обучения, образования и воспитания, направленной на достижение единой цели по формированию гармонично развитой личности. Самое главное в погоне за новым сохранить фундаментальность знаний в процессе обучения и не растерять весь накопленный опыт преподавания, всего лишь, обогатить новыми формами и методами обучения. Все составляющие педагогического процесса находятся в тесной взаимосвязи, не теряя при этом своей автономности, особенностей, присущих только этому внутреннему процессу. Основной функцией воспитания является воспитание, функцией образования - образование, а функцией обучения, соответственно, обучение. Стать образованным человеком, не получив фундаментальных основ знаний, должного воспитания и образования, осуществляя при этом, познавательную умственную активность обучающегося невозможно. Осуществляя педагогический процесс, необходимо четко выделять ту часть педагогического воздействия, которая является актуальной в настоящее время. В процессе обучении, где основной целью является передача ученикам определенных фундаментальных основ знаний, педагогу нужно четко осознавать, что приобретенное в процессе обучения будет иметь непосредственное влияние на познавательную самостоятельность, мыслительную активность, а особенно самовоспитание обучающегося. Познание нового во многом определяет отношение обучающегося к образованию, рождает мотивацию к лучшему восприятию изучаемого естественно-научного цикла дисциплин, формирует цели, к которым относятся: обогащение внутреннего мира, формирование познавательной самостоятельности, стремление к получению новых знаний в процессе обучения.

Целостность, общность, единство - главные характеристики педагогического процесса, подчеркивающие подчинение всех составляющих его процессов единой цели. [6]

Педагогический процесс на всем пути обучения в образовательной школе контролируется и управляется. Весь образовательный процесс преследует одну цель формирование личности, обладающей заданными качествами, присущими процессу обучения, как с использованием новых методик и технологий, а также различных способов изложения специально подготовленных материалов.

Социокультурное содержание обучения в области естественно-научных дисциплин состоит в усвоении фундаментальных знаний, навыков, умений как форм 
освоения образовательных ценностей. В новой парадигме образования учебно-воспитательный процесс должен опираться на формирование культурных базовых способностей, которые являются результатом освоения культурных способов мышления и деятельности, приобретенных за время обучения с помощью новых форм и методик обучения в образовательном процессе.

Разрабатывая концепцию целостного подхода к обучению естественно-научного цикла дисциплин, отметим, что сегодня физико- математическое образование закономерно обретает гуманистическую ориентацию. Отказавшись от своего привычного, изложения сухих формулировок законов и положений, фундаментальные науки постепенно поворачивается к обучающимся теми ее пока еще скрытыми гранями, при восприятии которых становятся явными общечеловеческие и конкретно личностные ценности науки. Она дает возможность ученикам получать научные знания, не в готовом виде, а в процессе поиска истины и развития в соответствующем культурном контексте образовательного пространства. [7]

Из выше сказанного можно сделать вывод, что со- временные условия образовательного процесса, характеризуются обращением к личности обучающегося, развитию лучших его качеств.

Основываясь на философских, методологических основах подхода к обучению дисциплин естественно-научного цикла, отметим роль следующих фактов научного, общекультурного и психолого-педагогического значения:

- новое осмысление фундаментализации науки, согласно которому естественно-научный цикл дисциплин (математика, физика, химия и др) обладает общезначимой ценностью в качестве важнейшего элемента современной культуры;

- эти ценности, безусловно, заложены в самом образовательном процессе обучения и следует предпринять определенные методические усилия, чтобы они стали очевидными, доступными и привлекательными для обучаемых;

- учебное знание обретает смысл культуры, если способствует положительному само изменению обучающегося, формирует и развивает его как субъекта познавательного процесса.

\section{ЛИТЕРАТУРА}

1. Х Ходусов А.Н. Фундаментализация профессионального образования //Ученые записки. Электронный научный журнал.-2017№3(43).-Курск.

2. Лапин Н.И. Проблема социокультурной трансформации // Вопросы философии. 2000. - № 6

3. Касьян А.А. Гуманитаризация образования: некоторые теоретические предпосылки // Педагогика. - 1998. - № 2. - С.17-22

4. Подаева Н. Г. Обучение математике в контексте социокультурной концепции образования/ №2 2010 - педагогика. психология

5. Суханов А. Концепция фундаментализации высшего образования и ее отражение в ГОСах // Высшее образование в России. - 1996. - №3. - С.15-24

6. Митина Л.М. Психология развития конкурентоспособной личности. - М.: МЛДЭК, 2002. - 400с.

7. Абакумова С.И. Формирование исследовательской компетентности студентов инженерного вуза при изучении математики: автореферат дис. кандидата педагогических наук : 13.00.08 / Абакумова Светлана Ивановна; [Место защиты: Сев.-Кавказ. гос. техн. ун-т]. - Ставрополь, 2009. - 23 с. 